\title{
Herpes zoster oticus with multiple cranial nerve involvement: a rare presentation
}

\author{
Talukdar $\mathbf{J}^{1}$, Harshvardhan ${ }^{2}$ \\ ${ }^{1}$ Dr. Jeumon Talukdar, M. S. (E.N.T.), Senior Consultant, ${ }^{2}$ Dr. Harshvardhan, D.L.O., DNB Trainee; All authors are \\ affiliated with Department of E.N.T., Down Town Hospital, Guwahati, Assam, India.
}

Address for Correspondence: Dr. Harshvardhan, Email: dr.harshvardhan.hv@ gmail.com

\begin{abstract}
Herpes zoster oticus is characterized by vesicular rash on the concha, EAC and pinna with a lower motor neuron type palsy of the facial nerve. The disease is a result of reactivation of dormant viral particles either in the geniculate ganglion of the Facial nerve or the spiral and vestibular ganglia of the vestibulocochlear nerve. It is a very painful condition which is usually associated with palsy of the Facial (VII) nerve. We report a case of Herpes zoster oticus involving the V, VII, VIII, IX and X cranial nerves.
\end{abstract}

Key words: Herpes zoster oticus, Cranial nerve involvement, Varicella zoster, Facial palsy, Palatal palsy, Vocal cord palsy

\section{Introduction}

Herpes zoster oticus is characterized by a herpetic vesicular rash on the concha, external auditory canal or pinna with a lower motor neuron palsy of the ipsilateral facial nerve. It is caused by Varicella Zoster Virus. [1] It was first described by James Ramsey Hunt in 1907. It is also commonly known as Ramsey Hunt Syndrome Type II, as Hunt described three neurological syndromes [2]. The disease is a result of the reactivation of the dormant viral particles either in the geniculate ganglion of the facial nerve or the spiral and vestibular ganglia of the vestibulocochlear nerve. [1] It is commonly associated with palsy of the Facial Nerve, however involvement of glossopharyngeal nerve and vagus nerve is seen in $2.9 \%$ cases. [2] We report a case of Herpes zoster oticus involving the V, VII, VIII, IX and $\mathrm{X}$ cranial nerves.

\section{Case Report}

A male aged 66 years presented to our out-patient department with complains of Left sided earache since 1 week. He developed facial weakness 4 days later along with hoarseness of voice and difficulty in swallowing. He noted rashes over his left ear on the same day. He also gave history of associated nasal regurgitation and ringing sensation in his left ear. Patient also complained of giddiness on the day of his presentation to us.

The patient was a known Hypertensive with a Blood pressure of 170/100 $\mathrm{mmHg}$ on presentation. He was recently diagnosed to be suffering from Hypothyroidism for which he was taking oral Thyroxine $50 \mu \mathrm{g}$ tablets. He was not a diabetic. However, he gave history of Chicken Pox infection during childhood. On Otological examination, we noticed multiple vesicular rashes on the left Pinna, Pre-auricular and Post-auricular region and the external auditory canal. The tympanic membrane on the left side was congested.

Facial nerve examination revealed Grade IV palsy according to the House-Brackmann grading system on the left side. There was no spontaneous nystagmus and ocular movements were normal. The corneal reflex was however, diminished on the left side.

\footnotetext{
Manuscript received $27^{\text {th }}$ June 2016

Reviewed: $10^{\text {th }}$ July 2016

Author Corrected: $26^{\text {th }}$ July 2016

Accepted for Publication $14^{\text {th }}$ August 2016
} 
Oro-pharyngeal examination revealed multiple pin-head sized ulcers on tongue and left buccal mucosa and soft palate. Uvula was deviated to the right side and left palatal palsy was found. On Indirect Laryngoscopic examination, the patient was found to have left sided vocal cord palsy which was confirmed with fibre-optic naso-pharyngo-laryngoscopy. This finding was suggestive of left recurrent laryngeal nerve palsy.

All routine hematological investigations were within normal limits. Serum thyroid stimulating hormone was found to be raised. A magnetic resonant imaging of brain and cerebellopontine angle was done which suggested of age related cerebral atrophy

Based on the history and our clinical examination, we came to a diagnosis of Herpes zoster oticus. On basis of investigations we had ruled out other causes like Skull base tumors and malignant otitis externa.

We started the patient on Valacyclovir $1 \mathrm{gm}$ thrice a day along with acyclovir ointment for local application over the lesion of left ear. Prednisolone $60 \mathrm{mg}(1 \mathrm{mg} / \mathrm{Kg}$ body weight $)$ was started on the second post admission day after ruling out diabetes mellitus. Eye patch and artificial tear was started to prevent exposure keratitis. Diclofenac and Gabapentin was started for pain. Methylcobalamin was given. Ryle's tube feeding was given to prevent aspiration. Physiotherapy for facial nerve was started. After 1 week of therapy, the vesicular rashes and oral ulceration had disappeared. Corneal reflex returned back to normal and pharyngeal sensation was present. The facial weakness had improved to HB grade III. However, palatal palsy and vocal cord palsy still persisted. Patient was discharged on oral medications with ryle's tube feeding.

After 6 weeks of follow-up, now patient is able to swallow comfortably without the need for Ryle's tube feeding. The palatal palsy has recovered. However, residual facial weakness (HB grade II) still persists.

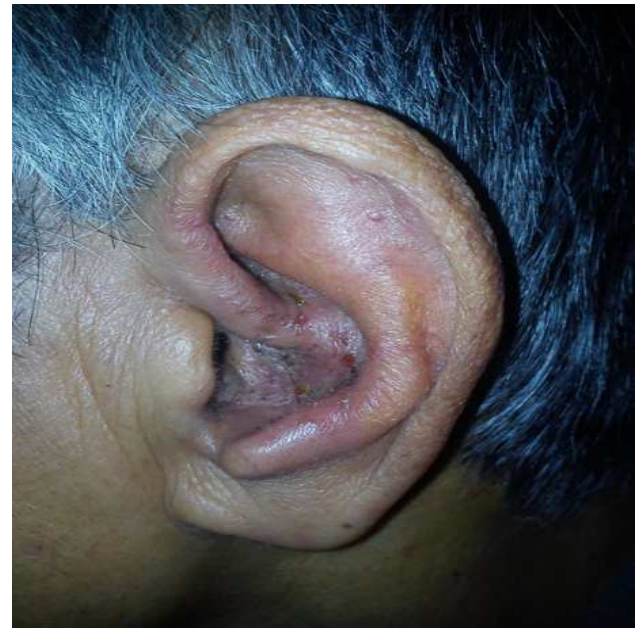

Fig-1: Vesicular rashes on left pinna

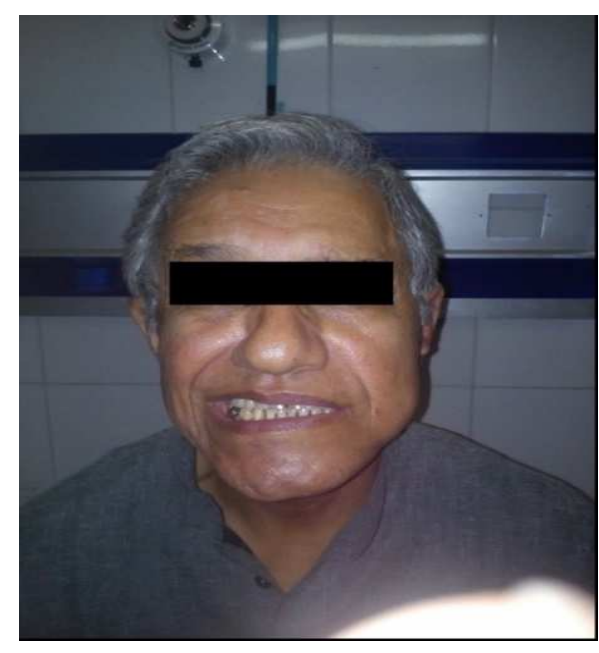

Fig-2: deviation of angle of mouth on clenching of teeth

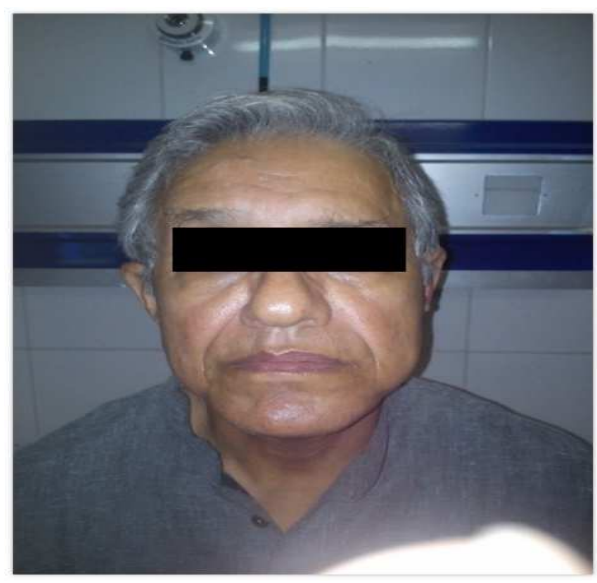

Fig-3: loss of wrinkling of forehead and slight angle of mouth deviation at rest. 


\section{Discussion}

Herpes Zoster Oticus was first described by Ramsay Hunt in 1907. It is also called Ramsay Hunt Syndrome Type II. Hunt described three syndromes: [2]

- Type I: Dyssynergia Cerebellaris Progressiva, a rare, degenerative, neurological disorder characterized by myoclonus epilepsy, intention tremor, progressive ataxia and cognitive impairment.

- Type II: Herpes Zoster Oticus, a disorder that is caused by the reactivation of pre-existing Varicella zoster virus in the geniculate ganglion, a nerve cell bundle, of the facial nerve.

- Type III: Hunt's disease or Artisan's palsy, an occupationally induced neuropathy of the deep palmar branch of the ulnar nerve.

According to available literature, Herpes Zoster Oticus forms the second most common cause of unilateral facial nerve palsy after Bell's palsy, with an incidence of $12 \%$ [1]. The syndrome is most commonly associated with VIIth cranial nerve palsy but may involve other cranial nerves as well, as seen in the present case where V, VII, VIII, IX and X cranial nerve were involved.

Similar presentation has been reported by Laurisden et al in 2010 where involvement of V, VII, VII, IX, X and XII cranial nerves was seen. Sun WL in 2011 reported another case with V VII, VII, IX and X cranial nerve involvement. Sugita-Kitajima A in 2009 also reported a case with VII, VIII, IX and $\mathrm{X}$ cranial nerve involvement. Another case was reported by Lunge $S$ et al in 2014 have VII, VIII, IX and X cranial nerve involvement $[3,4,5]$.

If untreated, $60 \%$ patients develop a complete facial paralysis within a week. If palsy is complete only $10 \%$ will have full recovery if nerve conduction studies reveal absence of neural activity ten days later. If palsy is complete $66 \%$ patients will recover completely. Overall $50 \%$ adult and $80 \%$ children have full recovery [1].

The recommended treatment for this disease includes Anti-viral therapy with oral Acyclovir $800 \mathrm{mg}$ five times a day for 10-12 days or Valacyclovir 1gm thrice a day. Oral Prednisolone should also be started in a dose of 1 $\mathrm{mg} / \mathrm{kg}$ body weight for 1 month with gradual tapering of dose. Early treatment is also known to reduce post herpetic neuralgia significantly.

In a retrospective study it was seen that in patients where therapy was started within 3 days of onset of symptom, $75 \%$ patients achieved a complete recovery.

Where as in patients where therapy was started within 8 days of onset of symptom, only $30 \%$ showed complete recovery. Thus, it is recommended to start the therapy at the earliest [1].

In 2006, US FDA approved the Zoster Vaccine, a live attenuated vaccine. This vaccine is now recommended for all individuals above 50 years of age.

This vaccine can be administered as a single $0.65 \mathrm{ml}$ subcutaneous injection over deltoid.

Zostavax Efficacy and Safety Trial (ZEST) showed a $69.8 \%$ reduction in risk of developing herpes zoster in subjects who were administered the zoster vaccine as compared to a placebo, with very few systemic side effects [6].

\section{Conclusion}

Herpes zoster oticus is a common disease in older age groups. It has now been established as a more common cause of unilateral facial palsy than was earlier thought to be. Also involvement of other lower cranial nerves can occur with this condition. Early and prompt initiation of therapy give improved outcomes. With the advent of vaccine we should hope for a reduction in the overall incidence of this disease.

Funding: Nil, Conflict of interest: None initiated, Permission from IRB: Yes

\section{References}

1. A. Simon Carney, Herpes Zoster Oticus, ScottBrown's Otorhinolaryngology, Head and Neck Surgery, Hodder Arnold, $7^{\text {th }}$ edition, 2008, 3379-3382.

2. Sweeney CJ, Gilden DH. Ramsay Hunt syndrome. J Neurol Neurosurg Psychiatry. 2001 Aug;71(2):149-54.

3. Lauridsen AG, Mirz F. [Herpes zoster oticus with cranial nerve affection]. Ugeskr Laeger. 2010 Oct $11 ; 172(41): 2849-51$. 
4. Sugita-Kitajima A, Sato S, Koizuka I, Ramsay Hunt Syndrome with cranial polyneuropathy involving cranial nervesVII, VIII, IX \& X, Nihon Jibiinkoka Gakkai Kaiho. 2009 Sep;112(9):656-9

5. Patil V, Borkar M, Saoji N. Rare case report of multiple cranial nerve involvement in Ramsay Hunt syndrome. Egyptian Dermatology Online Journal. 2014 Jun $1 ; 10(1)$.
6. Vesikari T, Hardt R, Rümke HC, Icardi G, Montero J, Thomas S, Sadorge C, Fiquet A. Immunogenicity and safety of a live attenuated shingles (herpes zoster) vaccine $($ Zostavax $®)$ in individuals aged $\geq 70$ years: a randomized study of a single dose vs. two different twodose schedules. Hum Vaccin Immunother. 2013 Apr;9(4):858-64. doi: 10.4161/hv.23412. Epub 2013 Jan 14.

\section{How to cite this article?}

Talukdar J, Harshvardhan. Herpes zoster oticus with multiple cranial nerve involvement: a rare presentation. Int J Med Res Rev 2016;4(8):1430-1433.doi:10.17511/ijmrr.2016.i08.24. 